\title{
Unified Control of a Buck Converter for Wide-Load-Range Applications
}

\author{
Christoph H. van der Broeck, Student Member, IEEE, Rik W. De Doncker, Fellow, IEEE, \\ Sebastian A. Richter, and Jochen von Bloh
}

\begin{abstract}
A new discrete-time state feedback controller is presented, which allows high-bandwidth voltage control of a buck converter for any load condition, whether it operates in discontinuous conduction mode (DCM), continuous conduction mode (CCM), or at the boundary of these regions. This makes the buck converter applicable for a wide range of applications. For the control design process, two large-signal models, which represent the buck converter's discrete time dynamics in CCM and DCM, are developed. A simple proportional-integral regulator is used for the voltage control of the converter. The operation mode is detected and the voltage controller is connected in cascade to a current controller in CCM or to a nonlinear state feedback decoupling structure in DCM. In this paper, the modeling and design of the proposed control topology are introduced and its performance is demonstrated in simulation and experiment.
\end{abstract}

Index Terms-Buck converter control, continuous conduction mode (CCM), control synthesis, converter modeling discrete time control, discontinuous conduction mode (DCM).

\section{NOMENCLATURE}

$\begin{array}{ll}v_{\mathrm{pwm}} & \text { PWM voltage }(\mathrm{V}) . \\ v_{m} & \text { Manipulated input voltage }(\mathrm{V}) . \\ i_{\mathrm{Lf}} & \text { Inductor current }(\mathrm{A}) \text {. } \\ v_{\mathrm{Cf}} & \text { Capacitor voltage }(\mathrm{V}) . \\ i_{\text {load }} & \text { Load current }(\mathrm{A}) . \\ V_{\mathrm{dc}} & \text { DC-link voltage }(\mathrm{V}) . \\ L_{f}, C_{f}, R_{f} & \text { Inductance }(\mathrm{H}), \text { capacitance }(\mathrm{F}) \text { and resistance } \\ & (\Omega) \text { of the buck converter. } \\ \omega_{0} & \text { Natural frequency of the } L C \text { filter }\left(\mathrm{s}^{-1}\right) . \\ Z_{0} & \text { Impedance of the } L C \text { filter }(\Omega) . \\ T_{s}, T_{\mathrm{pwm}} & \text { Sampling period, PWM period }(\mathrm{s}) . \\ f_{s}, f_{\mathrm{pwm}} & \text { Sampling frequency, PWM frequency }(\mathrm{Hz}) . \\ d & \text { Duty cycle. } \\ \varepsilon & \text { Current decay interval. } \\ K_{\mathrm{op}}, K_{\mathrm{oi}} & \text { Observer state feedback gains }\left(\Omega^{-1}, \Omega^{-1} \mathrm{~s}^{-1}\right) .\end{array}$

Manuscript received November 25, 2014; revised March 12, 2015; accepted April 25, 2015. Date of publication May 12, 2015; date of current version September 16, 2015. Paper 2014-IPCC-0838.R1, presented at the 2014 IEEE Applied Power Electronics Conference and Exposition, Fort Worth, TX, USA, March 16-20, and approved for publication in the IEEE TRANSACTIONS ON InDUSTRY APPLICATIONS by the Industrial Power Converter Committee of the IEEE Industry Applications Society.

C. H. van der Broeck and R. W. De Doncker are with the Institute for Power Electronics and Electrical Drives (ISEA), RWTH Aachen University, 52062 Aachen, Germany (e-mail: post@ isea.rwth-aachen.de).

S. A. Richter and J. von Bloh are with AixControl GmbH, 52062 Aachen, Germany (e-mail: info@aixcontrol.de).

Color versions of one or more of the figures in this paper are available online at http://ieeexplore.ieee.org.

Digital Object Identifier 10.1109/TIA.2015.2431994

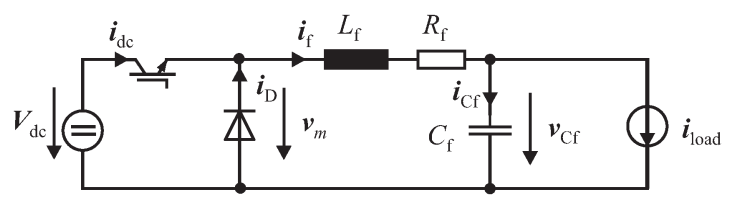

Fig. 1. Circuit diagram of the buck converter.

$\begin{array}{ll}K_{v}, K_{\mathrm{vi}} & \text { Voltage PI regulator gains }\left(\Omega^{-1}, \Omega^{-1} \mathrm{~s}^{-1}\right) . \\ K_{0} & \text { Open loop gain. } \\ r_{\tau} & \text { Regulator gain ratio } r_{\tau}=K_{\mathrm{vi}} T_{s} / K_{v} . \\ K_{f} & \text { Command filter gain }\left(\mathrm{s}^{-1}\right) . \\ R_{a} & \text { Current feedback gain }(\Omega) . \\ A_{1}, B_{1}, B_{\mathrm{ve}} & \text { Discrete time model coefficients }(10-12) . \\ \hat{x} & \text { Estimated value of } x . \\ x^{*} & \text { Reference value of } x .\end{array}$

\section{INTRODUCTION}

$\mathbf{F}$ OR today's industrial and commercial voltage supplies, buck converters are a popular choice. They provide a lowcost and robust topology, exhibit well-known steady-state and dynamic properties [1]-[8], and the design procedures for these converters have been intensively studied [9]-[18]. However, the control of a one quadrant buck converter (see Fig. 1) over a wide load range and varying voltage transfer ratios is challenging, because the converter dynamics change significantly between continuous conduction mode (CCM) and discontinuous conduction mode (DCM). Furthermore, the topology does not allow reverse power flow. Thus, an increased output voltage cannot be actively reduced, which means that an overshoot of the output voltage has to be avoided or at least limited.

The starting point for the control design of a converter is a suitable model that captures the relevant dynamics of the system. Over the last decades, many different small-signal and large-signal modeling techniques have been proposed to describe the dynamics of a buck converter [1]-[7]. From those techniques, state-space averaging is the most accepted one. Applying state-space averaging in CCM, the converter exhibits a linear second-order characteristic [6], [7], whereas in DCM, it shows nonlinear first-order system dynamics [8]. A control algorithm, which shall be applicable over a wide load range, must be able to work with these varying dynamics.

The simplest control structure for a buck converter is a proportional-integral-differential (PID) voltage regulator. In [9] and [10], typical control design procedures, which are based on a small-signal model, are illustrated. Hence, these models 


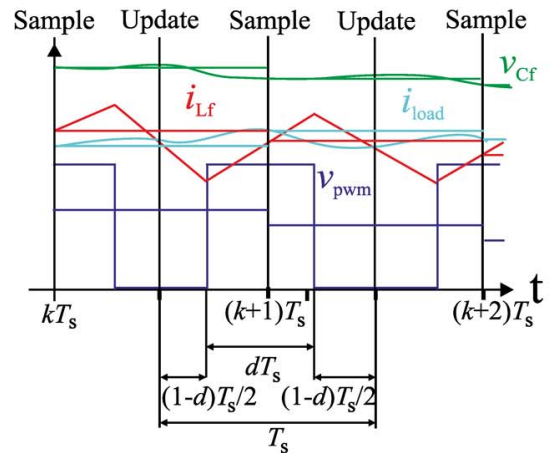

Fig. 2. Buck converter in CCM (left) and DCM (right) operation.

are only valid around a certain operation point [11]. The regions in which such a controller can be operated robust and safely can be identified according to [12] or [13], where it is also demonstrated that this simple control structure does not guarantee stable and well-behaved dynamics over a wide operation range. To overcome these problems, [14]-[16] suggest alternative control structures, which take into account the load dependent dynamics and improve the stability of the converter. However, these approaches are not suitable for a general design approach, as they do not take into account the change of the system dynamics that occurs when changing between CCM and DCM operation. Furthermore, they cannot be used to achieve a quasi-linear system behavior with a desired damping or dynamic stiffness, as they do not decouple the nonlinearity of the converter. In [17], a controller for a synchronous buck converter is proposed, based on the large-signal converter model, which enables operation in CCM and smooth transition to DCM. Unfortunately, this solution cannot be used for a conventional buck converter, because it requires a switch antiparallel to the converter diode.

The controller proposed in this paper overcomes these problems and allows the buck converter to be used for wideload-range applications. Based on two large-signal models describing the buck converter dynamics in CCM and DCM, a cascaded control structure with a single PI voltage controller is developed. The voltage regulator is connected to a current controller in CCM or to a nonlinear decoupling unit in DCM. The regulator is designed via the root locus method, such that in both operation modes the converter exhibits well-behaved dynamics and a smooth transition is guaranteed. This paper first presents the discrete time modeling for DCM and CCM. Then the control structure is proposed and the design of the state feedback gains is illustrated. Finally, results from simulations and experiments are presented.

\section{Modeling of the Buck Converter}

The development of an accurate model of the buck converter, which is independent of the operating point, is crucial to understand its dynamic behavior over a wide voltage transfer ratio and load range. As the operation mode of the converter changes at the boundary between CCM and DCM, it is not possible to use one single model for the entire load range. Therefore, separate models for CCM and DCM are developed first. The activation and deactivation of the semiconductor switch insulated-

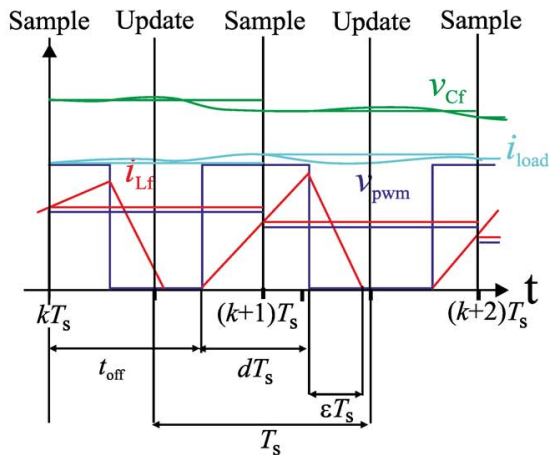

gate bipolar transistor (IGBT) in Fig. 1 allows applying a symmetrical regular sampled pulsewidth modulation (PWM) voltage $v_{\text {pwm }}$ at the input of the $L C$ filter, which comprises an inductor $L_{f}$, a capacitor $C_{f}$, and a parasitic series resistance $R_{f}$. If the current does not reach zero over one PWM interval in CCM, the system dynamics of the buck converter can be modeled applying large-signal state-space averaging, according to [5]. Thereby, all state and input quantities are averaged over one sample interval. The PWM voltage can be replaced by the so-called manipulated input voltage $v_{m}$. In a buck converter, $v_{m}$ is equal to the average reverse voltage across the diode within one switching cycle $T_{s}$

$$
v_{m}(t)=\bar{v}_{\mathrm{pwm}}(t)=d\left(k T_{s}\right) V_{\mathrm{dc}} .
$$

The averaging is tolerable because the $L C$ filter has low-pass filter characteristics. The sampling of the measured output voltage $v_{\mathrm{Cf}}$, input voltage $v_{\mathrm{dc}}$, the load current $i_{\text {load }}$, and the inductor current $i_{f}$ is synchronized with the symmetrical PWM. At the start of each sampling interval, the duty cycle $d$ is updated, whereas in the middle of the interval, the measured signals are acquired, as illustrated in Fig. 2. This process is referred to as synchronous sampling [19] and allows capturing the average current in each sampling interval. The dynamics of the $L C$ filter as a function of the manipulated input voltage and the load current can be described by (2) and (3)

$$
\begin{aligned}
L_{f} \frac{d}{d t} i_{f}(t) & =v_{m}(t)-v_{\mathrm{Cf}}(t)-R_{f} i_{f}(t) \\
C_{f} \frac{d}{d t} v_{\mathrm{Cf}}(t) & =i_{f}(t)-i_{\text {load }}(t) .
\end{aligned}
$$

In DCM, the diode of the buck converter does not allow a negative inductor current. Thus, the current remains zero until the IGBT is activated again, and no power is transferred for a time of $t_{0}=(1-\varepsilon-d) T_{s}$. A state block diagram of the buck converter model can be developed in the continuous time domain for CCM and DCM by enhancing the classical $L C$ filter model of a full-bridge converter [20] with a nonlinear resistance (see Fig. 3). When the filter current remains positive, the nonlinearity does not occur and has no impact on the second-order system dynamics of the filter. However, if the inductor current decays to zero before the end of the carrier interval, the diode, which is modeled as a nonlinear resistance, enforces that the current does not become negative. 


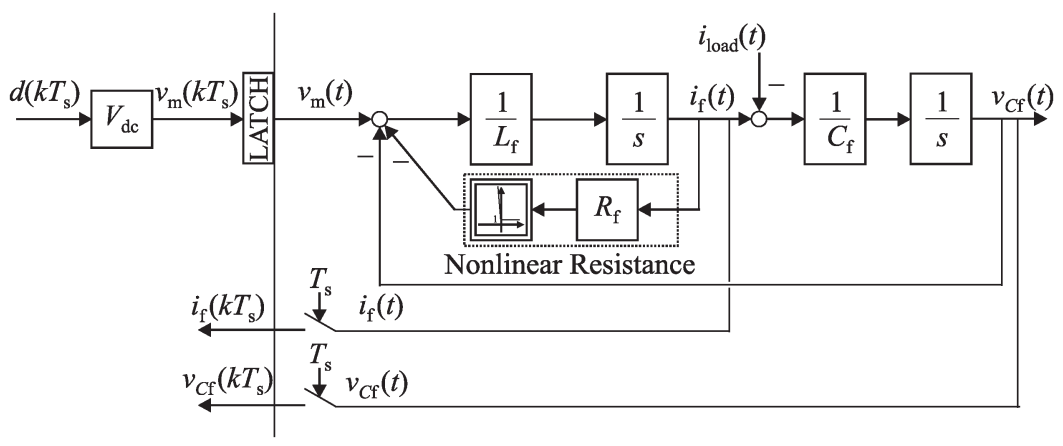

Fig. 3. State block diagram of the buck converter.

This harsh nonlinearity has a significant impact on the system dynamics of the converter. As the conduction time $t_{c}(t)=$ $(\varepsilon(t)+d(t)) T_{s}$ becomes a function of the operating conditions, classical space averaging cannot be used. To control the buck converter, accurate models for the buck converter operating in CCM and DCM need to be developed in the discrete time domain. Applying classical $z$-domain modeling techniques, the modulator dynamics and the second-order filter characteristics in CCM can be handled, whereas in DCM, a new modeling approach is introduced to capture its discrete time dynamics.

\section{A. CCM Discrete Time Modeling}

When the buck converter operates in the CCM, the differential equations (2) and (3) can be solved using initial conditions and assuming that the manipulated input voltage $v_{m}$ and a load current $i_{\text {load }}$ stay constant over the time interval [22]. The filter resistance is approximated to zero, which is a valid assumption as its impedance is very small in common applications. The resulting equations of current $i_{f}$ and voltage $v_{\mathrm{Cf}}$ as a function of the initial conditions are given by (4) and (5)

$$
\begin{aligned}
i_{f}(t)= & \frac{1}{Z_{0}} \sin \left(\omega_{0} t\right)\left(v_{m}(t=0)-v_{\mathrm{Cf}}(t=0)\right) \\
& +\cos \left(\omega_{0} t\right) i_{f}(t=0)+\left(1-\cos \left(\omega_{0} t\right)\right) i_{\text {load }}(t=0) \\
v_{\mathrm{Cf}}(t)= & \left(1-\cos \left(\omega_{0} t\right)\right) v_{m}(t=0)+Z_{0} \sin \left(\omega_{0} t\right) \\
& \times\left(i_{f}(t=0)-i_{\text {load }}(t=0)\right)+\cos \left(\omega_{0} t\right) v_{\mathrm{Cf}}(t=0) .
\end{aligned}
$$

The coefficients used in (4) and (5) are the characteristic impedance $Z_{0}=\sqrt{L_{f} / C_{f}}$ and the resonant frequency $\omega_{0}=$ $1 / \sqrt{L_{f} C_{f}}$ of the $L C$ filter. These equations can be used to formulate the difference equations (6) and (7), which indicate how the inductor current and the capacitor voltage at one sampling time $T_{s}$ ahead can be calculated based on the applied manipulated input voltage and load current

$$
\begin{aligned}
i_{f}\left((k+1) T_{s}\right)= & \frac{\sin \left(\omega_{0} T_{s}\right)}{Z_{0}}\left(v_{m}\left(k T_{s}\right)-v_{\mathrm{Cf}}\left(k T_{s}\right)\right)+\cos \left(\omega_{0} T_{s}\right) \\
& \times i_{f}\left(k T_{s}\right)+\left(1-\cos \left(\omega_{0} T_{s}\right)\right) i_{\text {load }}\left(k T_{s}\right) \\
v_{\mathrm{Cf}}\left((k+1) T_{s}\right)= & \left(1-\cos \left(\omega_{0} T_{s}\right)\right) v_{m}\left(k T_{s}\right)+Z_{0} \sin \left(\omega_{0} T_{s}\right) \\
& \times\left(i_{f}\left(k T_{s}\right)-i_{\text {load }}\left(k T_{s}\right)\right)+\cos \left(\omega_{0} T_{s}\right) v_{\mathrm{Cf}}\left(k T_{s}\right) .
\end{aligned}
$$

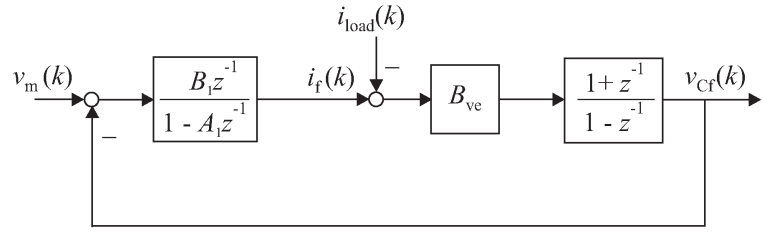

Fig. 4. State block diagram of the discrete time model in CCM.

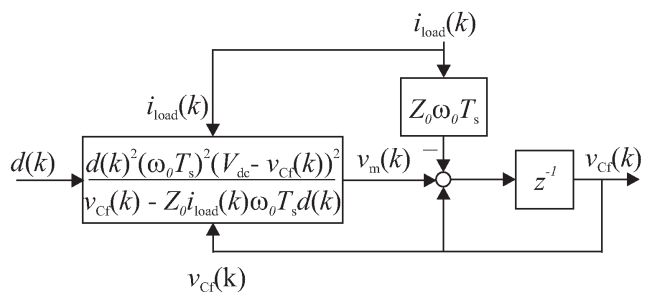

Fig. 5. Nonlinear discrete time model of the converter in DCM.

These difference equations can be $z$-transformed using the shift operator of the $z$-transformation and solved with the help of trigonometric identities resulting in the cross coupled $z$-domain model

$$
\begin{gathered}
I_{f}(z)=\frac{\sin \left(\omega_{0} T_{s}\right)}{Z_{0}} \frac{z-1}{1-\cos \left(\omega_{0} T_{s}\right) z^{-1}}\left(V_{m}(z)-V_{\mathrm{Cf}}(z)\right) \\
V_{\mathrm{Cf}}(z)=Z_{0} \tan \left(\frac{\omega_{0} T_{s}}{2}\right) \frac{1+z^{-1}}{1-z^{-1}}\left(I_{f}(z)-I_{\mathrm{load}}(z)\right)
\end{gathered}
$$

To abbreviate the CCM discrete time model, the following coefficients are introduced, which are used in the continuous time model of the buck converter depicted in Fig. 4

$$
\begin{aligned}
A_{1} & =\cos \left(\omega_{0} T_{s}\right) \\
B_{1} & =\frac{1}{Z_{0}} \sin \left(\omega_{0} T_{s}\right) \\
B_{\mathrm{ve}} & =Z_{0} \tan \left(\frac{\omega_{0} T_{s}}{2}\right) .
\end{aligned}
$$

\section{B. DCM Discrete Time Modeling}

In a next step, a discrete time model is developed for the DCM. It is the goal to derive a difference equation for the DCM operation of the buck converter, which calculates the capacitor 
TABLE I

INDUCTOR CURRENT AND CAPACITOR Voltage AT THE CHARACTERISTIC INSTANCES DURING ONE PWM PERIOD IN DCM

\begin{tabular}{|c|c|c|c|}
\hline & $t_{\mathrm{X}}=d T_{\mathrm{S}}$ & $t_{\mathrm{X}}=(\varepsilon+d) T_{\mathrm{S}}$ & $t_{\mathrm{x}}=T_{\mathrm{S}}$ \\
\hline$v_{\mathrm{Cf}}\left(k T_{s}+t_{\mathrm{X}}\right)$ & $\begin{array}{c}v_{\mathrm{Cf}}\left(k T_{\mathrm{s}}\right)- \\
Z_{0}{ }^{\omega}{ }^{d} \mathrm{~T}_{\mathrm{s}} i_{\operatorname{load}}\left(k T_{\mathrm{s}}\right)\end{array}$ & $\begin{array}{l}v_{\mathrm{Cr}}\left(k T_{\mathrm{s}}\right)\left(1-\left(\omega_{0} T_{\mathrm{S}}\right)^{2} d \varepsilon\right) \\
-\mathrm{Z}_{0}{ }^{\omega} 0_{\mathrm{S}}(\varepsilon+d) i_{\text {load }}\left(k T_{\mathrm{s}}\right) \\
\quad+\left(\omega_{0} T_{\mathrm{S}}\right)^{2} d \varepsilon V_{\mathrm{dc}}\end{array}$ & $\begin{array}{c}v_{\mathrm{cr}}\left(k T_{\mathrm{s}}\right)\left(1-\left(\omega_{0} T_{\mathrm{S}}\right)^{2} d \varepsilon\right)- \\
Z_{0} \omega_{0} T_{\mathrm{s}} i_{\text {load }}\left(k T_{\mathrm{s}}\right)+\left(\omega_{0} T_{\mathrm{s}}\right)^{2} d \varepsilon V_{\mathrm{dc}}\end{array}$ \\
\hline$i_{\mathrm{f}}\left(k T_{\mathrm{s}}+t_{\mathrm{X}}\right)$ & $\left(V_{\mathrm{dc}}-v_{\mathrm{Cf}}(k T \mathrm{~s})\right) \frac{d T_{\mathrm{S}} \omega_{0}}{Z_{0}}$ & $\begin{array}{c}-v_{\mathrm{Cr}}\left(k T_{\mathrm{s}}\right) \frac{T_{\mathrm{S}} \omega_{0}}{Z_{0}}(\varepsilon+d)+V_{\mathrm{dc}} \frac{T_{\mathrm{s}} \omega_{0}}{Z_{0}} \mathrm{~d} \\
+\left(\omega_{0} T_{\mathrm{S}}\right)^{2} d \varepsilon i_{\text {load }}\left(k T_{\mathrm{s}}\right) \stackrel{!}{=} 0\end{array}$ & 0 \\
\hline
\end{tabular}

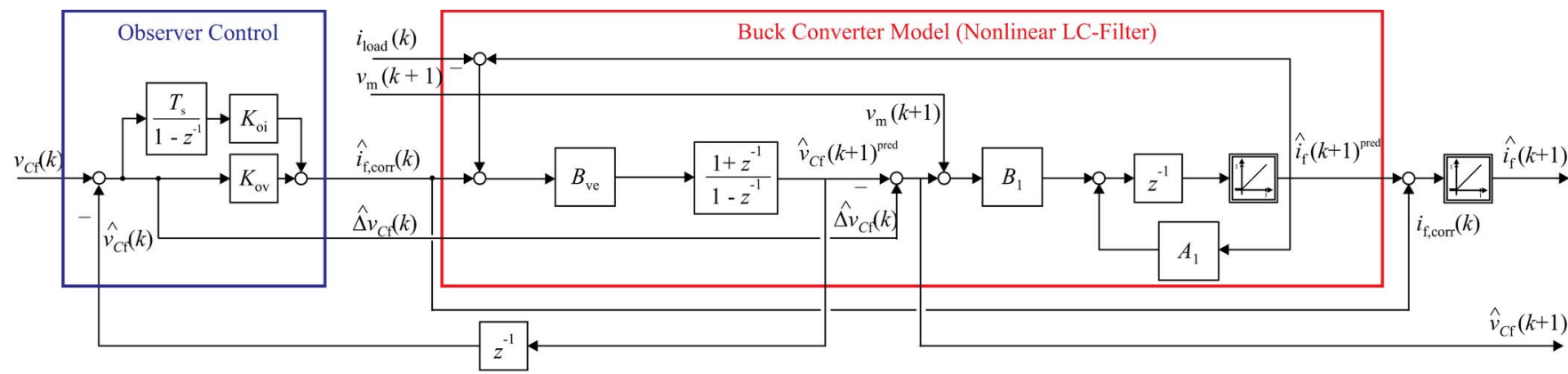

Fig. 6. Predictive nonlinear observer structure for state estimation of the buck converter in CCM and DCM.

voltage one time step $T_{s}$ ahead based on the voltage itself, the load current, and the duty cycle. It is assumed that the resonant frequency of the $L C$ filter is low compared with the sampling frequency, thus $\omega_{0} T_{s} \ll 1$. For most buck converter designs, this constraint does not present a significant limitation. The assumption allows simplifying the difference equations of the $L C$ filter, which results in

$$
\begin{aligned}
v_{\mathrm{Cf}}(t) & \approx v_{\mathrm{Cf}}(t=0)+Z_{0} \omega_{0} t\left(i_{f}(t=0)-i_{\text {load }}(t=0)\right) \\
i_{f}(t) & \approx i_{f}(t=0)+\left(v_{m}(t=0)-v_{\mathrm{Cf}}(t=0)\right) \frac{\omega_{0}}{Z_{0}} t .
\end{aligned}
$$

These simplified equations are used to determine the dynamics of the buck converter in DCM over one carrier interval in detail. The entire DCM model of the buck converter is depicted as state block diagram in Fig. 5. The starting point of the calculation is the instant when the IGBT is switched on.

During the length of the active voltage pulse $t_{a}=d T_{s}$ the current increases up to its peak value, of which the calculation is shown in Table I. According to the model's assumption the output voltage is only affected by the load current during that time span. Subsequently, the current decays to zero. Evaluating $\varepsilon$ each sampling time (15), it can be predicted whether the converter operates in $\mathrm{DCM}(\varepsilon+d<1)$ or $\mathrm{CCM}(\varepsilon+d>1)$ during the next PWM carrier interval

$$
\varepsilon\left(k T_{s}\right)^{\text {pred }}=\frac{\left(V_{\mathrm{dc}}-v_{\mathrm{Cf}}\left(k T_{s}\right)\right) d\left(k T_{s}\right)}{v_{\mathrm{Cf}}\left(k T_{s}\right)-Z_{0} \omega_{0} T_{s} d\left(k T_{s}\right) i_{\mathrm{load}}\left(k T_{s}\right)} .
$$

Based on the current at $t=(\varepsilon+d) T_{s}+t_{\text {off }}$, it is possible to develop a difference equation of the voltage at the end of the PWM interval $v_{c}\left((k+1) T_{s}+t_{\text {off }}\right)$ as function of the system variable $v_{\mathrm{Cf}}\left(k T_{s}+t_{\mathrm{off}}\right)$ at the beginning of the PWM interval (16). Clearly, in DCM, the buck converter exhibits nonlinear first-order dynamics

$$
\begin{array}{r}
v_{\mathrm{Cf}}\left((k+1) T_{s}\right)=\frac{d\left(k T_{s}\right)^{2}\left(\omega_{0} T_{s}\right)^{2}\left(V_{\mathrm{dc}}-v_{c}\left(k T_{s}\right)\right)^{2}}{v_{\mathrm{Cf}}\left(k T_{s}\right) Z_{0} \omega_{0} T_{s} i_{\text {load }}\left(k T_{s}\right) d\left(k T_{s}\right)} \\
-Z_{0} \omega_{0} T_{s} i_{\text {load }}\left(k T_{s}\right)+v_{\mathrm{Cf}}\left(k T_{s}\right) .
\end{array}
$$

\section{OBSERVER-BASED STATE ESTIMATION}

For a high performance and smooth operation of the buck converter in both operation modes, a nonlinear predictive observer structure that provides zero lag estimates of the inductor current and the output voltage has been developed. In particular, the tracking of the average inductor current is of importance for detection of an overcurrent and also to be capable of rapid transitions between CCM and DCM. In [23], it is shown that a simple regular sampling of the inductor current is not meaningful. In this case, the sampled current does not correspond to the short-time average value, as the current shape is not symmetrical with respect to the PWM carrier.

The method proposed in this paper only requires the measurement of the load current and the output voltage and estimates the average inductor current accurately even if the inductor current becomes discontinuous. The use of this observer makes it possible to eliminate a complex acquisition and $\mathrm{AD}$ conversion of the discontinuous inductor current. The state block diagram of the observer is depicted in Fig. 6. In CCM, the discrete time $L C$-filter model of the observer is fed by the 

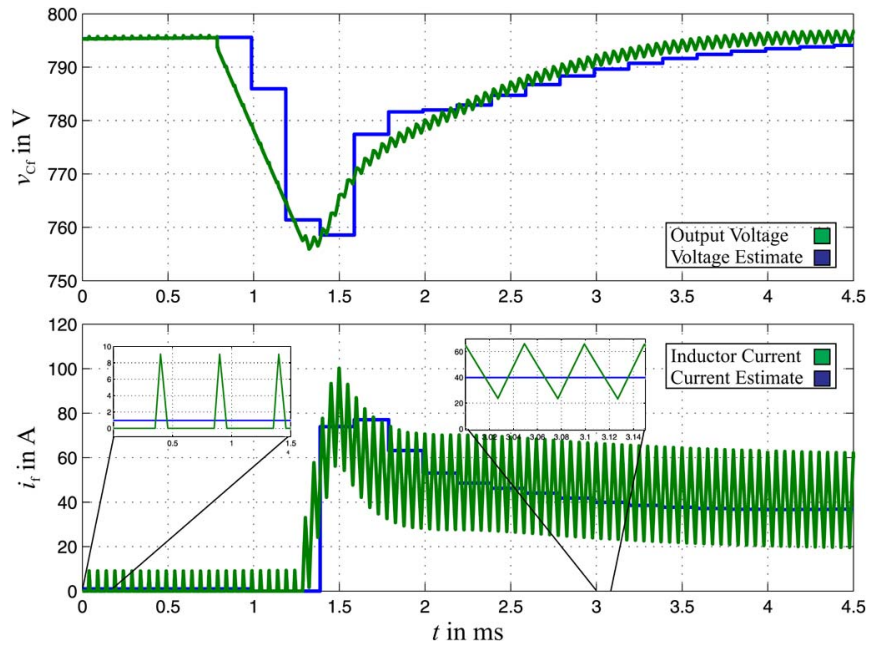

Fig. 7. Simulation of the observer during a load current step.

future manipulated input voltage $v_{m}\left((k+1) T_{s}\right)$ and the load current measurement $i_{\text {load }}\left(k T_{s}\right)$. It is not forced in the nonlinear range and thus provides very accurately predicted estimates of the inductor current $i_{f}\left(k T_{s}\right)$ and the output voltage $v_{\mathrm{Cf}}\left(k T_{s}\right)$. The prediction of these quantities is of great importance to compensate for the control dead time between the sampling process and the duty cycle update. Minor modeling and measurement deviations are compensated by the observer controller structure, which compensates deviations of the output voltage estimate with deadbeat response via a feedforward path, whereas the inductor current is compensated within the bandwidth of the observer's PI regulator.

The PI regulator feedback gains $K_{\mathrm{oi}}$ and $K_{\mathrm{ov}}$ can be evaluated using the root locus method. They are selected such that the EVs of the observer are well damped, and the bandwidth is reasonably high. As soon as the buck converter enters DCM, the limitation that is included in the inductor model and that models the nonlinear resistance ensures that the filter current does not become negative. Thereby, the characteristics of the nonlinear resistance introduced in the continuous time model of the buck converter (see Fig. 3) are embodied in the $L C$-filter model. Of course, the discrete time model loses a lot of its precision, as the nonlinearity cannot be precisely modeled in a discrete time model. For this reason, the observer controller needs to compensate for errors in the inductor current quite strongly. By adding the integral feedback loop $\hat{v}_{\mathrm{Cf}}(k)$, it is ensured that the observer achieves an accurate steady-state estimate of the averaged inductor current even in DCM.

The performance of the observer's state estimation during the transition between DCM and CCM is demonstrated in the simulation presented in Fig. 7. At $t=1 \mathrm{~ms}$, a load step is applied to the converter. As a result, the inductor current is increased and the converter changes the operation mode from DCM to CCM. It can be seen that the observer tuned to a bandwidth of $500-\mathrm{Hz}$ tracks the voltage and current with minor deviations. These deviations are forced to zero by the observer's integral feedback loop tuned to a bandwidth of $50 \mathrm{~Hz}$. It ensures that within a convergence time of $t_{\mathrm{conv}}=10 \mathrm{~ms}$, the initial error decays.
Thus, the observer is able to estimate the current and voltage accurately with nearly zero lag and zero steady-state error in both operation modes without any inductor current measurement.

\section{Control of the Buck Converter}

In the unified control approach, based on the models developed for CCM and DCM, two different internal control structures are used. In CCM, a cascaded current and voltage control loop is implemented, which needs to handle the secondorder dynamics of the converter in CCM. A nonlinear state feedback decoupling structure decouples the nonlinearity of the buck converter in DCM. Combining both controllers allows controlling the converter with a simple PI controller. In the following, the control structures for both operation modes are developed separately from each other based on the developed models, the PI regulator design is discussed, and finally, both controllers are merged to a unified control structure.

\section{A. Cascaded Control for CCM}

The developed discrete time $L C$ filter model is used to construct a cascaded discrete time control structure for CCM in analogy to the continuous time control structure presented in [20] and [21]. In the case of CCM, the behavior of the $L C$-filter buck converter is identical as in an H-bridge converter.

The developed predictive observer structure compensates the control dead time. As a result, the estimated capacitor voltage $\hat{v}_{\mathrm{Cf}}$ can be used to decouple the current loop from the output voltage accurately. The estimated inductor current can be fed back to decouple the impact of the capacitance on the inductor transfer function, which results in a voltage to current transfer function of an ideal forward Euler integration

$$
G_{\mathrm{dec}, \mathrm{i}}(z)=\frac{I_{f}(z)}{V_{m}^{*}(z)}=\frac{B_{1} z^{-1}}{1-z^{-1}}=\frac{\sin \left(\omega_{0} T_{s}\right)}{Z_{0}} \frac{z^{-1}}{1-z^{-1}} .
$$

The inductor current in CCM can be controlled with a proportional state feedback controller, whose state feedback gain $R_{a}$ can be determined as a function of the desired current loop bandwidth according to

$$
R_{a}=Z_{0} \frac{1-e^{-\omega_{b} T_{s}}}{\sin \left(\omega_{0} T_{s}\right)}
$$

The highest current state feedback gain possible is $R_{a}=B_{1}$, which results in a deadbeat response of the current. The voltage control loop (19) is closed by a PI regulator in cascade around a dead-beat current control loop

$$
G_{\mathrm{o}, \mathrm{v}}(z)=\frac{V_{\mathrm{Cf}}(z)}{I_{\mathrm{reg}}(z)}=B_{\mathrm{ve}} \frac{1+z^{-1}}{1-z^{-1}} z^{-1} .
$$

The PI regulator design must be designed to ensure good disturbance rejection ability and zero steady-state error. To achieve high-bandwidth command tracking, a command filter is used. Based on the reference current, the command filter calculates a consistent voltage and current reference, which are fed as command vector into the control structure. The entire CCM control structure is depicted in Fig. 8. 


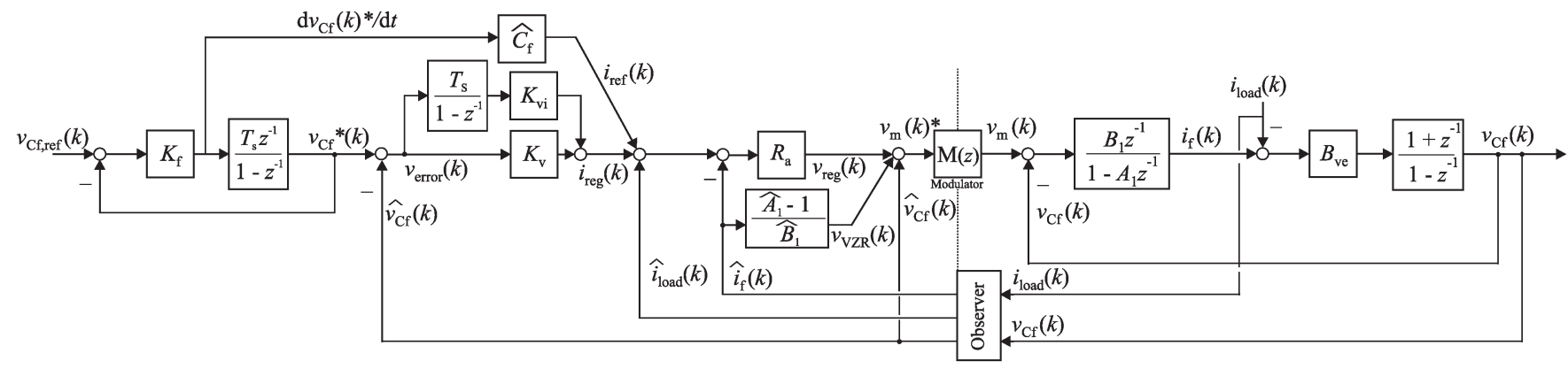

Fig. 8. Cascaded control structure for the buck converter in CCM.

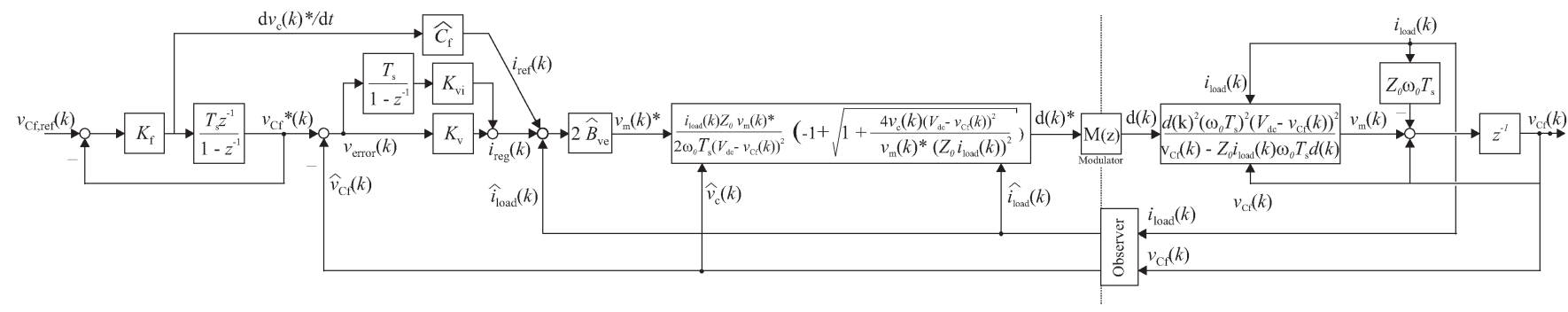

Fig. 9. Control structure of the buck converter in DCM based on a nonlinear state feedback decoupling.

\section{B. Nonlinear State Feedback Decoupling for DCM}

When the converter operates in the DCM, the nonlinear dynamics of the plant need to be decoupled to allow a PI voltage regulator to control the output voltage of the converter independent of the operation point. If the nonlinearity was not decoupled and the voltage was controlled by a PI regulator, the damping, parameter sensitivity, and the stiffness of the closedloop system would become operating point dependent.

It can be shown that the model nonlinearity can be inverted. This inversion is used to decouple the system dynamics as shown in Fig. 9. The resulting open-loop transfer function is scaled to achieve the identical dc-gain of the voltage transfer function, which is represented by

$$
G_{\mathrm{o}, \mathrm{v}}(z)=\frac{V_{\mathrm{Cf}}(z)}{I_{\mathrm{reg}}(z)}=2 \hat{B}_{\mathrm{ve}} \frac{z^{-1}}{1-z^{-1}} .
$$

Thereby, the identical PI voltage regulator, which is employed in the control of the CCM control structure, can be used for the control of the DCM operation. A smooth transition between the operation modes is guaranteed, if the PI regulator is designed properly.

\section{Design of the State Feedback Gains}

The design options for the PI regulator can be effectively explored using the root locus method. For this method, the open-loop transfer functions of the voltage loop in both operation modes (19), (20) and the transfer function of the PI regulator (21) are required. To optimize the system dynamics (e.g., dynamic stiffness, controller bandwidth), the open loop gain $K_{0}=B_{\mathrm{ve}} K_{p}$ needs to be maximized leading to an augmentation of the control bandwidth. Furthermore, it is advisable to push the integral state feedback gain via the regulator gain ratio $r_{\tau}=K_{\mathrm{vi}} T_{s} / K_{v}$ as high as possible to improve the low frequency stiffness of the system [19]. Well-behaved dynamics of the controlled system is obtained with an optimal damping $\xi=0.707$ for all eigenvalues (EV)

$$
G_{\mathrm{PI}}(z)=\frac{V_{\mathrm{reg}}(z)}{E_{\mathrm{VCf}}(z)}=K_{p}+\frac{K_{i} T_{s}}{1-z^{-1}}=K_{p}\left(1+\frac{r_{\tau}}{1-z^{-1}}\right)
$$

The root locus has been plotted for the closed-loop voltage control using 4 different regulator gain ratios $r_{\tau}$ for DCM and CCM (17), (18) (see Fig. 11). For $r_{\tau}=0.25$, the CCM root locus touches the optimal damping region at one point for $K_{0}=0.2$, whereas the DCM root locus is still deep in the optimal damping region. Therefore, this regulator gain ensures the best low frequency stiffness without violating the damping constraint, and it is selected as an optimal candidate for the PI-regulator design. The open loop gain is selected such that the eigenvalues do not leave the optimal damping region. The dominant closed-loop eigenvalues for CCM and DCM are marked by a red circle in the root locus plots. As the closedloop eigenvalues only slightly change their placement during the transition between CCM and DCM, a smooth operation mode transition is guaranteed.

\section{Unified Control Structure}

The final controller, which merges the CCM control and the DCM control in one unified control structure, is depicted in Fig. 10. Depending on the operation mode, either the DCM decoupling structure or the CCM current controller is connected to the PI voltage controller. Thereby, a proper converter control in the entire operation ranges of the converter in discontinuous 


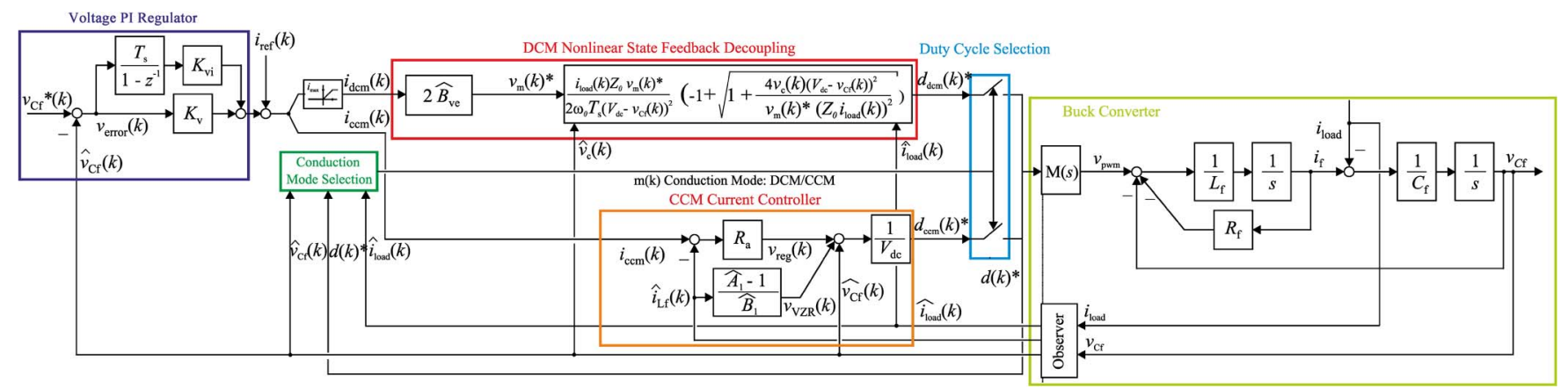

Fig. 10. State block diagram of the proposed unified control structure for the buck converter.
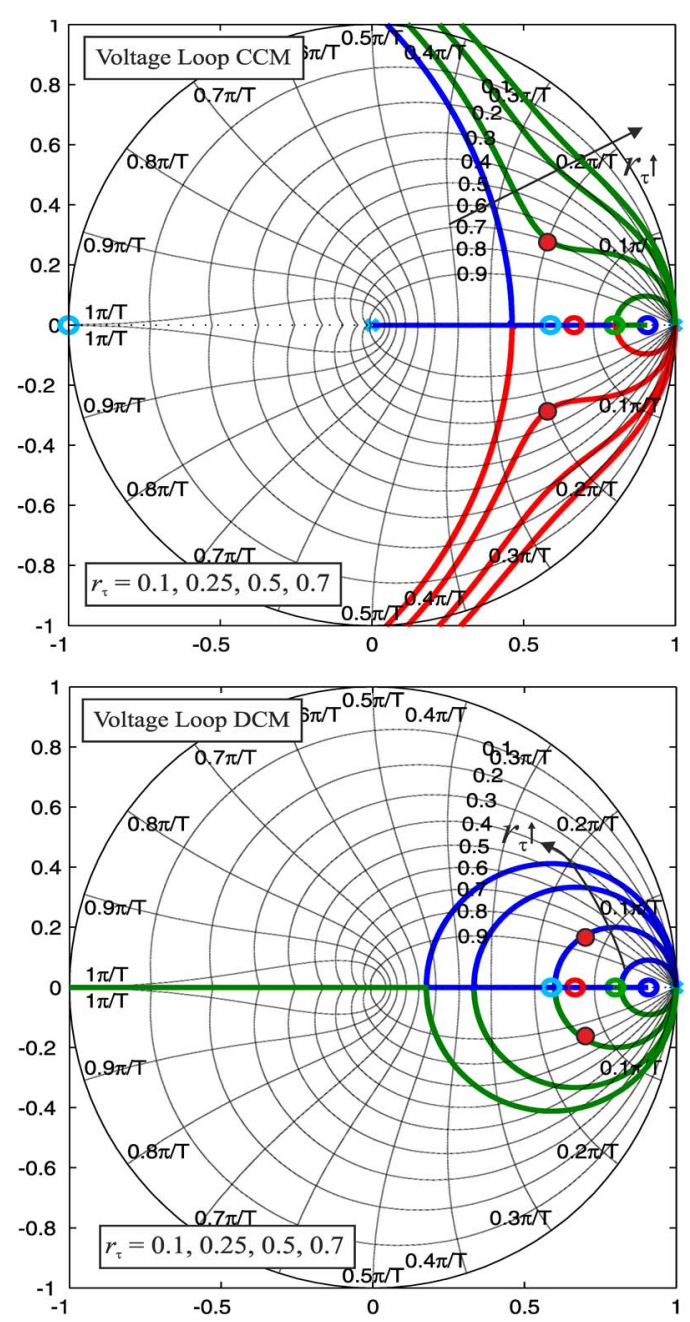

Fig. 11. Root locus-based calculation of the PI regulator gains for CCM and DCM with a final EV placement for $K_{0}=0.2$ and ratio $r_{\tau}=0.2$.

conduction mode as well as in continuous conduction mode and during the transition from one operation mode to another is ensured.

\section{Simulation Results}

To validate the control structure, which is introduced in this paper, a simulation has been set up in PLECS with the system parameters summarized in Table II. The buck converter controller needs to handle variations of the load current. To
TABLE II

BUCK CONVERTER PARAMETERS

\begin{tabular}{|l|l|}
\hline Inductance & $L_{\mathrm{f}}=0.5 \mathrm{mH}$ \\
\hline Capacitance & $C_{\mathrm{f}}=500 \mu \mathrm{F}$ \\
\hline DC-Link Voltage & $V_{\mathrm{dc}}=1000 \mathrm{~V}$ \\
\hline Control Frequency & $f_{\mathrm{s}}=5 \mathrm{kHz}$ \\
\hline PWM-Frequency & $f_{\mathrm{c}}=20 \mathrm{kHz}$ \\
\hline
\end{tabular}
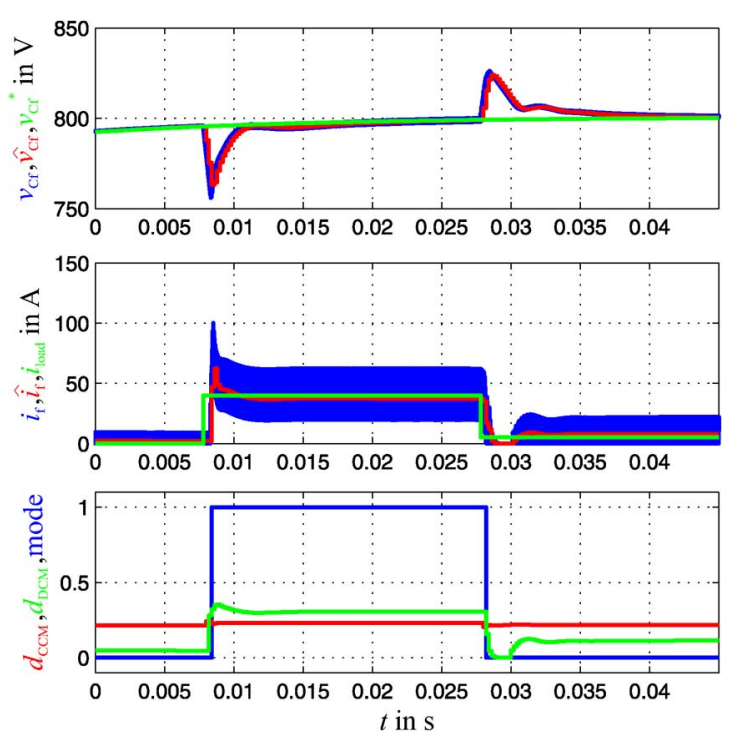

Fig. 12. Simulation: load chopping of the buck converter.

demonstrate the controller's capability of providing a stiff output voltage in the presence of load variations, the reaction of the controller to a load current step is shown in Fig. 12. The inductor current $i_{f}$ increases rapidly to compensate for the load current $i_{\text {load }}$ and to eliminate the error between the output voltage $v_{\mathrm{Cf}}$ and its reference $v_{\mathrm{Cf}}^{*}$. It takes $\Delta t=5 \mathrm{~ms}$ for the controller to compensate the load step until the voltage tracks its reference again. Meanwhile, the control detects the operation mode change and switches the duty cycle command for CCM and DCM at the right time instant. After the load current decays to $10 \mathrm{~A}$, the inductor current is forced to zero until the voltage overshoot is compensated by the load. Subsequently, the inductor current is slightly increased to settle in a steady state, where the converter operates in DCM.

For obtaining better insight in the transition between DCM and CCM, a load current ramp is applied to the converter, which 

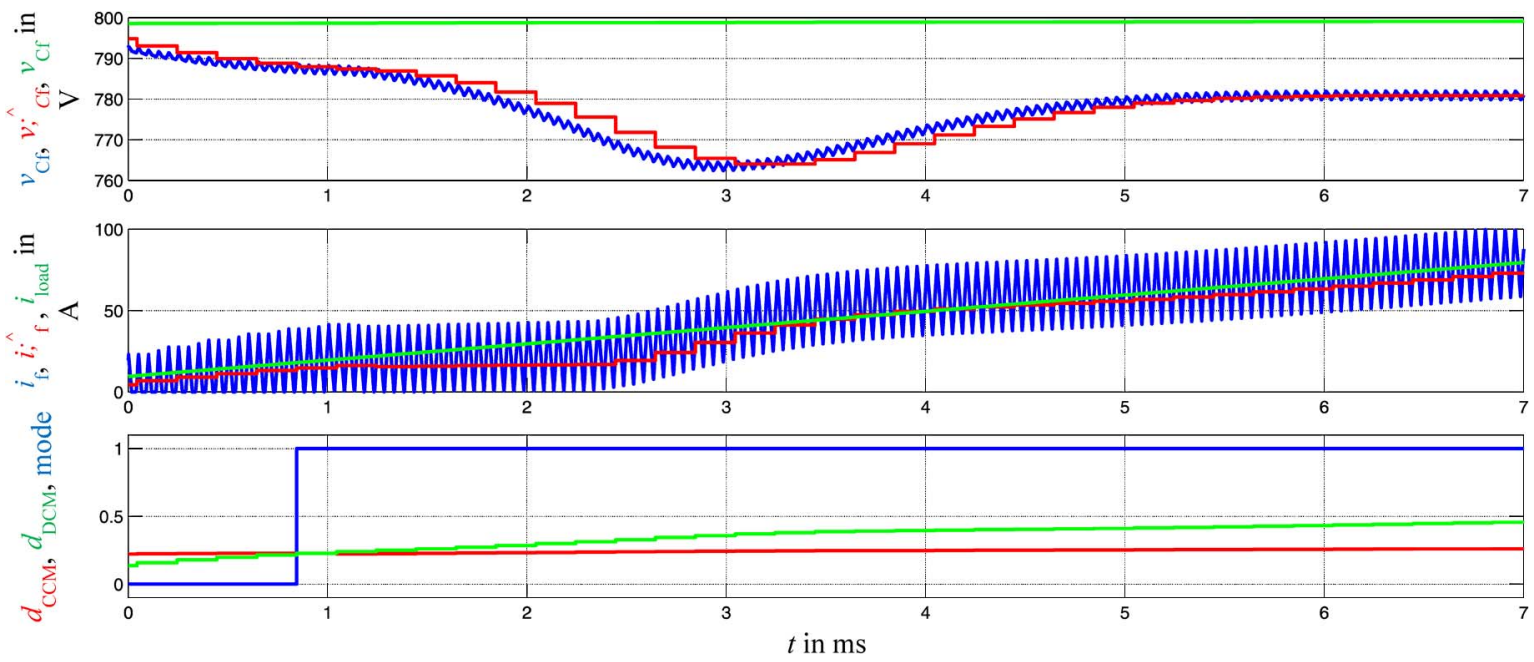

Fig. 13. Simulation: load ramp applied to the buck converter.
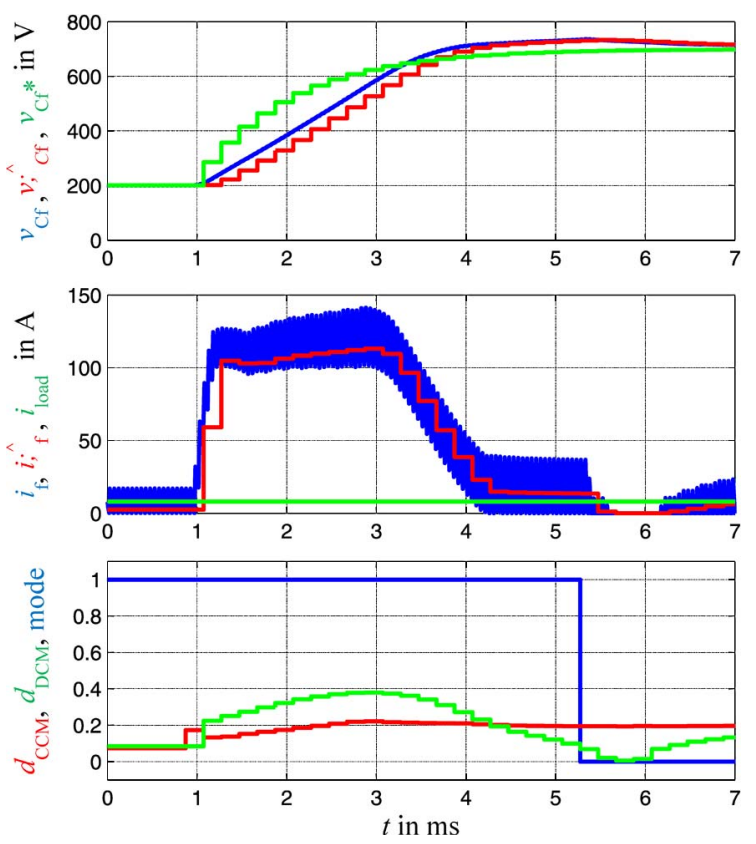

Fig. 14. Simulation: command tracking of the buck converter.

is depicted in Fig. 13. The controller accurately detects the transition instant between DCM and CCM and switches from the nonlinear decoupling structure to the current controller. Compared with DCM, the open loop amplification of the buck converter is augmented in CCM. Hence, after the transition of the operation mode, the duty cycle's slope is significantly reduced. After a short transient, the output voltage settles with $2.5 \%$ steady-state error. In Fig. 14 the command tracking of the proposed controller is examined. At $t=1 \mathrm{~ms}$ the reference voltage is increased from $200 \mathrm{~V}$ to $700 \mathrm{~V}$. A command filter with $150 \mathrm{~Hz}$ bandwidth converts the reference step in a consistent command vector, which is passed to the controller.

The buck converter is able to track the command trajectory closely with a small overshoot of $4 \%$. During this transient, the average current reaches the current limit of $100 \mathrm{~A}$ and remains at this level. Meanwhile an anti-wind-up stops the integration

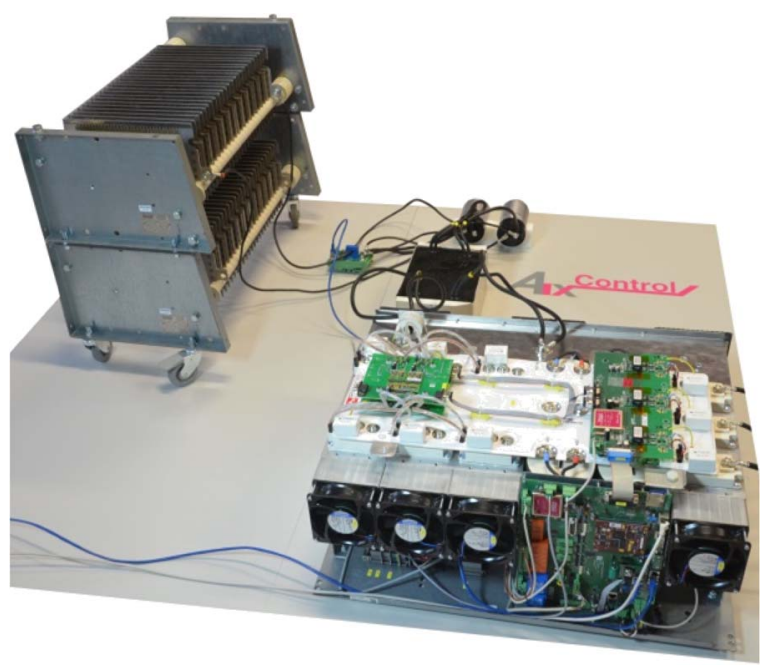

Fig. 15. Experimental setup of the buck converter.

process of the PI regulator. At the end of the voltage transient, the current is reduced, and finally, the converter is operated in DCM as, at the high output voltage, the load current is not high enough for CCM operation.

\section{EXPERIMENTAL RESULTS}

The experimental setup, including the studied buck converter connected to a resistive load and a three-phase PWM rectifier supplying the dc-link from the utility grid, is depicted in Fig. 15. The PWM rectifier provides a stiff dc-link as input voltage for the buck converter and is not further taken into account in this paper. The parameters of the buck converter are summarized in Table II. Its control algorithm is implemented on a XCP2100 board from AixControl $\mathrm{GmbH}$, which uses a $500 \mathrm{MHz}$ Blackfin DSP from Analog Devices and a Spartan 3 FPGA from Xilinx. The FPGA generates the PWM pattern, commands the control interrupts and the analog to digital conversion, whereas the digital control, state machine and communication is programmed on the DSP. The control board has been selected such that in 


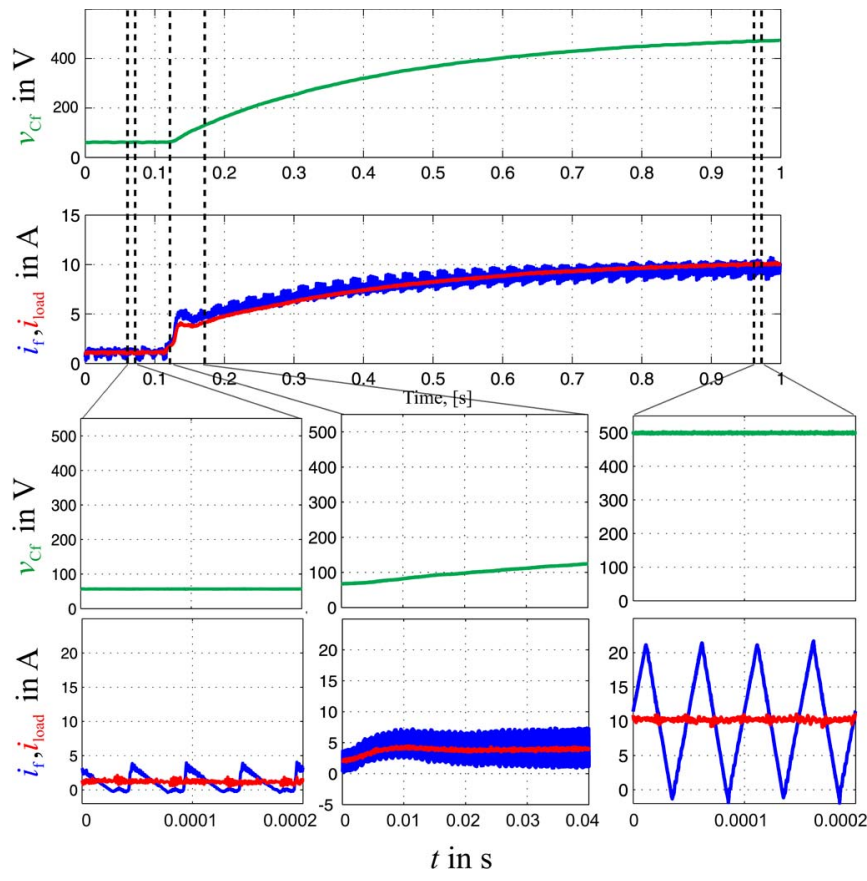

Fig. 16. Experiment: buck converter connected to a resistance between CCM and DCM during a reference voltage transient.

the particular power range of the studied voltage supply unit $(50 \mathrm{~kW})$ its costs are playing a minor role in comparison to the total system costs.

First, as it is depicted in Fig. 15, the buck converter was connected to a resistive load is examined to evaluate its performance at the transition between CCM and DCM operation. Next, the converter is connected to a nonlinear load to examine its capability of more realistic load conditions, e.g., when connected to a variable speed drive operating in six-step modulation.

\section{A. Resistive Load Operation}

In Fig. 16, it is shown how the buck converter operates during a reference voltage step from 60 to $500 \mathrm{~V}$. The reference voltage step is low-pass filtered by the command filter, resulting in a smooth voltage transient. Before the transient, the converter operates in DCM, as it can be seen from the discontinuous inductor current. It is shown that during the transient, the converter leaves DCM and enters CCM, whereas the output voltage remains unaffected from this operation mode change. After the transient, the buck converter operates in CCM. This experiment demonstrates that the proposed control structure enables a smooth transition between both operation modes of the converter and thus allows operating the buck converter within a wide load range.

\section{B. Nonlinear-Load Operation}

In a second experiment, the performance of the buck converter connected to a nonlinear load, requiring a wide supply voltage range, was examined. An output voltage ramp between 800 and $400 \mathrm{~V}$ is commanded to validate the capability of

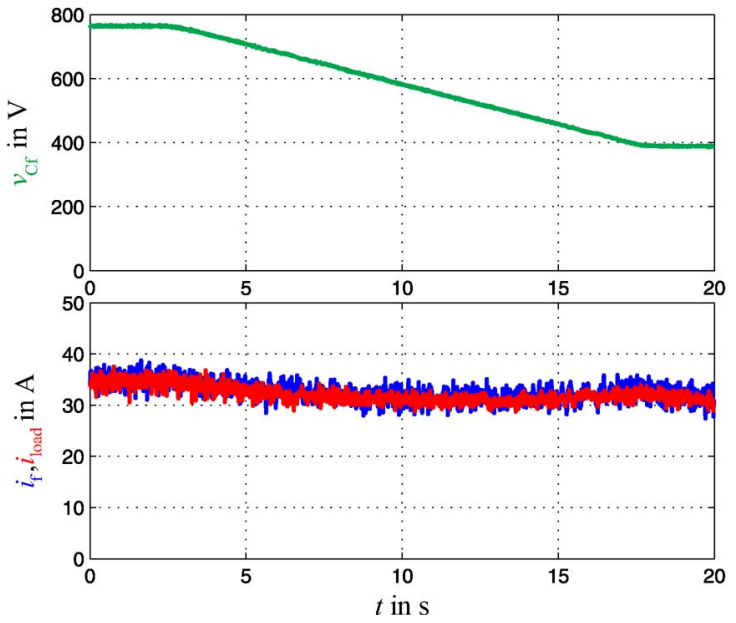

Fig. 17. Experiment: buck converter supplying a nonlinear load over a wide output voltage range.
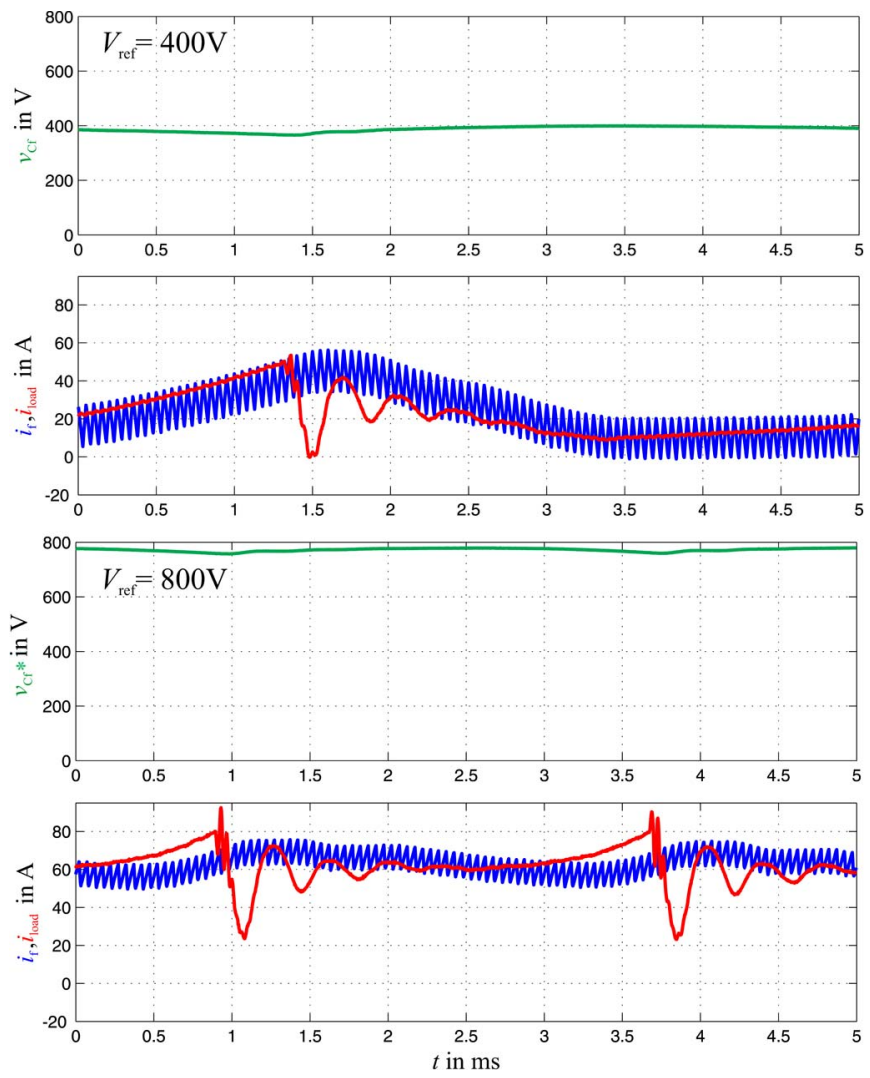

Fig. 18. Experiment: buck converter at a nonlinear load.

the converter to operate over a wide output voltage range. The ability of the converter to provide a stable output voltage over this large voltage range in the presence of strong load variations is shown in Fig. 17. The detailed operation of the converter at a reference voltage of 400 and $800 \mathrm{~V}$ is shown in Fig. 18. It can be seen that the converter is able to operate with a nonlinear load current. It compensates the load within its bandwidth, which results in a periodic increment and decay of the inductor current. The experimental results presented in Fig. 19 illustrate that the buck converter is also able to operate at the boundary region between CCM and DCM. 

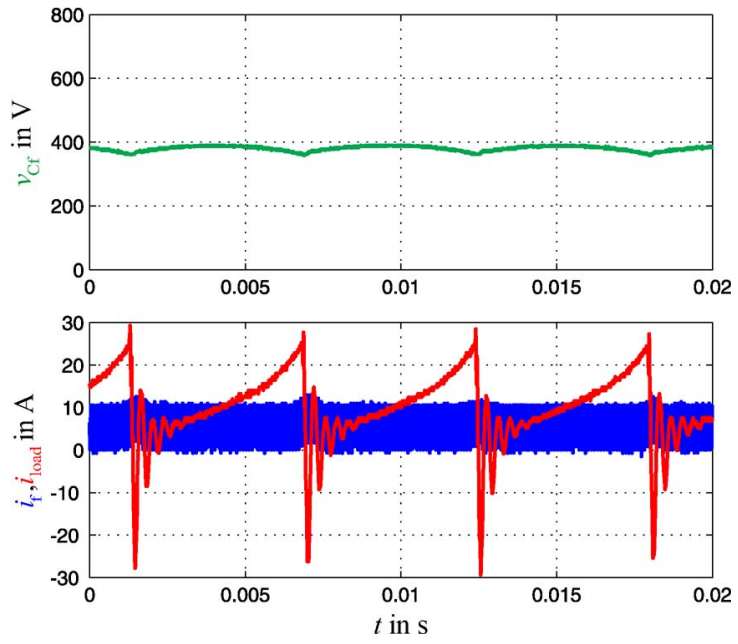

Fig. 19. Experiment: buck converter in the boundary operation.

The experiments show that the proposed control structure is able to provide a stiff adjustable output voltage for linear and even nonlinear loads. The major limitation of this power supply is the operation at very small output voltages e.g., $v_{C}^{*}<$ $0.05 V_{r}$. Due to the limited resolution of the PWM and dead time effects, it is difficult to modulate voltages accurately in this operation range such that it cannot be handled accurately. However, this is a limitation given by the buck converter topology and can be hardly avoided in a 50-kW converter system.

\section{SUMmary}

A new control structure that allows the stable and stiff operation of buck converters within a wide load range has been proposed. It provides a unified high-performance voltage control in DCM and CCM with a smooth transition between both operation modes. The modeling process, the control design synthesis, and the implementation of the control structure have been illustrated in detail. Finally, its performance has been verified by simulation and experiment. It has been shown that with the introduced controller the buck converter can be used to supply a variable output voltage with high stiffness for nonlinear load applications.

\section{REFERENCES}

[1] V. Vorperian, "Simplified analysis of PWM converters using model of PWM switch-Part I: Continuous conduction mode," IEEE Trans. Aerosp. Electron. Syst., vol. 26, no. 3, pp. 490-496, May 1990.

[2] V. Vorperian, "Simplified analysis of PWM converters using model of PWM switch-Part II: Discontinuous conduction mode," IEEE Trans. Aerosp. Electron. Syst., vol. 26, no. 3, pp. 497-505, May 1990.

[3] D. Czarkowski and M. K. Kazimierczuk, "Energy-conservation approach to modeling PWM DC-DC converters," IEEE Trans. Aerosp. Electron. Syst., vol. 29, no. 3, pp. 1059-1063, Jul. 1993.

[4] N. Femia and V. Tucci, "On the modeling of PWM converters for large signal analysis in discontinuous conduction mode," IEEE Trans. Power Electron., vol. 9, no. 5, pp. 487-496, Sep. 1994.

[5] R. D. Middlebrook and S. Cuk, "A general unified approach to modeling switching-converter power stages," Int. J. Electron., vol. 42, no. 6, pp. 521-550, Jun. 1977.

[6] J. Mahdavi, A. Emaadi, M. D. Bellar, and M. Ehsani, "Analysis of power electronic converters using the generalized state-space averaging approach," IEEE Trans. Circuits Syst. I, Fundam. Theory Appl., vol. 44, no. 8, pp. 767-770, Aug. 1997.
[7] K. Natarajan and M. Yektaii, "Modeling of DC-DC buck converters for large-signal frequency response and limit cycles," IEEE Trans. Circuits Syst. II, Exp. Briefs, vol. 53, no. 8, pp. 712-716, Aug. 2006.

[8] R. D. Middlebrook, "Small-signal modeling of pulse-width modulated switched-mode power converters," Proc. IEEE, vol. 76, no. 4, pp. 343-354, Apr. 1988.

[9] R. W. Erickson and D. Maksimović, Fundamentals of power electronics, 2nd ed. Norwell MA, USA: Kluwer, 2004.

[10] S. Buso, "Design of a robust voltage controller for a buck-boost converter using $\mu$-synthesis," IEEE Trans. Control Syst. Technol., vol. 7, no. 2, pp. 222-229, Mar. 1999.

[11] T. Nabeshima and K. Harada, "Large-signal transient responses of a switching regulator," IEEE Trans. Aerosp. Electron. Syst., vol. AES-18, no. 5, pp. 545-551, Sep. 1982.

[12] M. Hankaniemi, M. Karppanen, and T. Suntio, "Dynamical characterization of voltage-mode controlled buck converter operating in CCM and DCM," in Proc. 12th Int. Power Electron. Motion Control Conf., 2006, pp. 816-821.

[13] C. H. Rivetta, A. Emadi, G. A. Williamson, R. Jayabalan, and B. Fahimi, "Analysis and control of a buck DC-DC converter operating with constant power load in sea and undersea vehicles," IEEE Trans. Ind. Appl., vol. 42, no. 2, pp. 559-572, Mar./Apr. 2006.

[14] C. M. Liaw and S. J. Chiang, "Robust control of multimodule currentmode controlled converter," IEEE Trans. Power Electron., vol. 8, no. 4, pp. 455-465, Oct. 1993.

[15] G. Zhou, J. Xu, Y. Jin, and J. Sha, "Stability analysis of V2 controlled buck converter operating in CCM and DCM," in Proc. ICCCAS, Chengdu, China, Jul. 2010, pp. 551-555.

[16] Y. Zhao, W. Qiao, and D. Ha, "A sliding-mode duty-ratio controller for DC/DC buck converters with constant power loads," IEEE Trans. Ind. Appl., vol. 50, no. 2, pp. 1448-1458, Mar./Apr. 2014.

[17] D. Hirschmann, S. Richter, C. Dick, and R. W. De Doncker, "Unified control strategy covering CCM and DCM for a synchronous buck converter," in Proc. 22nd Annu. IEEE APEC, Feb./Mar. 2007, pp. 489-494.

[18] S. Saggini, M. Ghioni, and A. Geraci, "An innovative digital control architecture for low-voltage, high-current dc-dc converters with tight voltage regulation," IEEE Trans. Power Electron., vol. 19, no. 1, pp. 210-218, Jan. 2004.

[19] C. H. van der Broeck, R. W. De Doncker, S. A. Richter, and J. von Bloh, "Discrete time modeling, implementation and design of current controllers," in Proc. IEEE ECCE, Sep. 2014, pp. 540-547.

[20] M. J. Ryan, W. E. Brumsickle, and R. D. Lorenz, "Control topology options for single-phase UPS inverters," IEEE Trans. Ind. Appl., vol. 33, no. 2, pp. 493-501, Mar./Apr. 1997.

[21] M. J. Ryan and R. D. Lorenz, "A high performance sine wave inverter controller with capacitor current feedback and "Back-EMF," decoupling," in Proc. 26th Annu. IEEE PESC, Jun. 1995, pp. 507-513.

[22] K. Hongrae, M. W. Degner, J. M. Guerrero, F. Briz, and R. D. Lorenz, "Discrete-time current regulator design for AC machine drives," IEEE Trans. Ind. Appl., vol. 46, no. 4, pp. 1425-1435, Jul./Aug. 2010.

[23] S. F. Lim and A. M. Khambadkone, "A simple digital DCM control scheme for boost PFC operating in both CCM and DCM," IEEE Trans. Ind. Appl., vol. 47, no. 4, pp. 1802-1812, Jul./Aug. 2010.

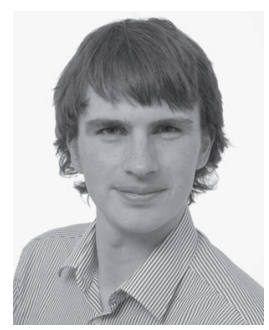

Christoph H. van der Broeck (S'11) received the B.Sc. and M.Sc. degrees in electrical engineering from RWTH Aachen University, Aachen, Germany, in 2010 and 2013, respectively, where he has been working towards a Ph.D. degree in the Institute for Power Electronics and Electrical Drives (ISEA), since January 2014.

From 2011 to 2012, he was with the Wisconsin Electric Machines and Power Electronics Consortium at the University of Wisconsin, Madison, WI, USA, as a Fulbright Scholar. Between 2012 and 2013, he was with AixControl GmbH working on control design of power converters. His research interests include the modeling and control of power electronic converters and drives. 


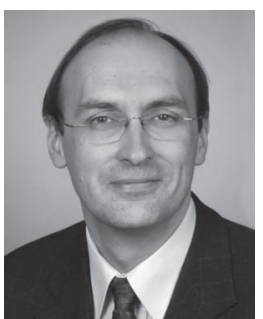

Rik W. De Doncker (F'01) received the Ph.D. degree in electrical engineering from the Katholieke Universiteit Leuven, Leuven, Belgium, in 1986.

In 1987, he was appointed as a Visiting Associate Professor with the University of Wisconsin, Madison, WI, USA. After a short stay as an Adjunct Researcher with the Interuniversity Microelectronics Centre, Leuven, he joined, in 1989, the Corporate Research and Development Center, General Electric Company, Schenectady, NY, USA. In 1994, he joined Silicon Power Corporation, a former division of General Electric as the Vice President of Technology. In 1996, he became a Professor with RWTH Aachen University, Aachen, Germany, where he currently leads the Institute for Power Electronics and Electrical Drives. Since 2006, he has been the Director of the E.ON Energy Research Center, RWTH Aachen University.

Dr. De Doncker was the President of the IEEE Power Electronics Society (PELS) in 2005 and 2006. He was the founding Chairman of the German IEEE Industry Applications Society (IAS)/PELS Joint Chapter. In 2002, he was the recipient of the IEEE IAS Outstanding Achievement Award. In 2008, he received the IEEE PES Nari Hingorani Custom Power Award. In 2009, he led a VDE/ETG Task Force on Electric Vehicles. In 2010, he received an honorary doctor degree from TU Riga, Latvia. In 2013, he received the IEEE William E. Newell Power Electronics Award.

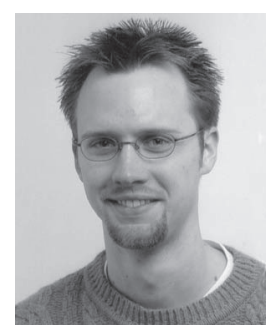

Sebastian A. Richter received the Ph.D. degree in electrical engineering from RWTH Aachen University, Aachen, Germany, in 2013.

He was a Research Associate with the Institute for Power Electronics and Electrical Drives (ISEA), RWTH Aachen University. He manages the group Control and Simulation at AixControl GmbH, Aachen. His research interests include control of power electronic converters, renewable energy, and power quality.

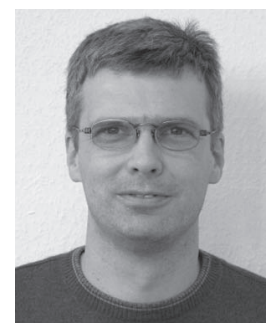

Jochen von Bloh received the Ph.D. degree in electrical engineering from RWTH Aachen University, Aachen, Germany, in 2001.

Until 2002, he led the research group for power electronics as Chief Engineer at the Institute for Power Electronics and Electrical Drives (ISEA). In 2002, he founded AixControl GmbH, Aachen, a company specializing in rapid power prototyping tools, power electronic design, and test systems for power electronic applications. His research interests include control of power electronic converters, power quality, and electromagnetic interference issues. 